\title{
De strijd der twee zielen in het werk van Walter Schubart
}

\begin{abstract}
Author:
Hans Ester ${ }^{1}$

Affiliation:

${ }^{1}$ Radboud University,

Nijmegen, The Netherlands

Correspondence to:

Hans Ester

Email:

j.ester@glazenkamp.net

Postal address:

1 Wisent Street, 6532AN

Nijmegen, The Netherlands

Dates:

Received: 09 Oct. 2012

Accepted: 29 Oct. 2012

Published: 14 Dec. 2012

How to cite this article: Ester, H., 2012, 'De strijd der twee zielen in het werk van Walter Schubart', Literator 33(2), Art. \#401, 5 pages. http://dx.doi.org/10.4102/ lit.v33i2.401
\end{abstract}

(C) 2012. The Authors. Licensee: AOSIS OpenJournals. This work is licensed under the Creative Commons Attribution License.
Dit essay is een verkenning van de actualiteit van het werk van Walter Schubart (1897- \pm 1941$)$, een bijkans onbekende cultuurfilosoof uit Letland. De schrijver gaat vooral in op de belang van Schubarts programma van geestelijke vernieuwing en zijn sterk intrigerende visie voor de Europese mens van vandaag. Als tegenwicht voor de metafysische egoïsme van de Europese mens vindt Schubart in Rusland, en vooral bij Dostojevsky, een levende gevoel van verbondenheid met het geheel die Europa weer gezond sal maken. De twintigste eeuw is voor Walter Schubart het strijdperk tussen het prometheïsche tijdperk van het afvallen van God en de beheersing der aarde enerzijds en het johanneïsche tijdperk van het Messiaanse oerbeeld dat handelt vanuit het verlangen naar heling en liefde anderzijds. Ondanks critiek op Schubarts opvattingen over de cultuurgeschiedenis, legt de schrijver de nadruk op het verrassend actuele wijze waarop Schubarts cultuurkritiek de huidige westerse cultuur een spiegel voorhoudt.

The struggle between two souls in the work of Walter Schubart. This essay explores the relevance of the work of Walter Schubart (1897- \pm 1941$)$, a virtually unknown cultural philosopher from Lithuania, for today. The writer focuses on the importance of Schubart's programme of spiritual rebirth and on his intriguing vision for the people of Europe today. To counterbalance the metaphysical egotism of Europe, Schubart finds in Russia, and in Dostoyevsky in particular, a living consciousness of a relation to the whole that could heal Europe. The twentieth century is for Schubart a battlefield between, on the one hand, the promethean period of deserting God focusing on the earth, and on the other hand, the johannean period of the Messianic era that acts out of a desire for charity and healing. Despite criticism of Schubart's somewhat simplistic views of cultural history, the author emphasises the surprising topical manner in which Schubart's cultural critique confronts modern Western culture with a critical reflection of itself.

\section{Inleiding}

De naam Walter Schubart lijkt op een geheime code tussen ingewijden, terwijl niet-ingewijden bij het horen van deze naam hun schouders ophalen. Walter Schubart was hoogleraar cultuurgeschiedenis aan de universiteit van Riga in Letland. Schubart werd in 1897 in Sonneberg in Thüringen geboren en stierf vermoedelijk in 1941 of tijdens een der jaren daarna in Siberië. Hij was vrijwilliger tijdens de Eerste Wereldoorlog, studeerde rechten en emigreerde in 1933 naar Riga. Daar doceerde hij. In 1940 werd Letland als gevolg van het Molotov-Ribbentrop-pact deel van de Sovjet-Unie. In 1941 volgde deportatie van Walter Schubart naar Siberië.

Ik heb geen bron kunnen vinden met behulp waarvan ik Schubart als mens kon leren kennen. Hij was met een Russische aristocrate getrouwd. Hadden de Schubarts kinderen? Indien ja, zijn die door de Russen geliquideerd of gedeporteerd? Dat er zo weinig bekend is over het leven van Walter Schubart, vindt zijn oorzaak in het feit dat Europa in grote beroering verkeerde op het moment waarop de belangstelling voor zijn ideeën groeide. Reizen was vanaf 1939 vrijwel onmogelijk en daarmee viel voor hem de mogelijkheid weg om in West-Europa lezingen te houden. In het Duitse Rijk bestond die mogelijkheid niet, omdat Schubarts ideeën sterk afweken van de ideologie van het nationaal-socialisme. De vraag is of Schubarts intrigerende visie op het menselijk bestaan aan de vooravond van de Tweede Wereldoorlog krachtig genoeg werd geacht om een tegenwicht te kunnen bieden tegen het communisme enerzijds en het nationaalsocialisme anderzijds. Ik heb geen informatie kunnen vinden over onderzoekers in het huidige Letland die de open plekken in Schubarts leven proberen op te vullen met feitelijke informatie. Het is denkbaar dat de titel van Schubarts belangrijkste werk in Letland de verkeerde associatie van verheerlijking van Russische expansiezucht opwekt.

\section{Een dwingend programma tot geestelijke vernieuwing}

Mijn nieuwsgierigheid naar de mens Walter Schubart is het directe gevolg van ethische en religieuze gedachten binnen zijn werk. Dat is niet erg omvangrijk, maar het presenteert zich zo 
duidelijk met een programma, een programma van geestelijke vernieuwing dat je meer wilt weten over zijn visie op het menselijk bestaan. Mijn diepste motief was om bij Schubart een tegenwicht te vinden tegen de Anglo-Amerikaanse cultuur die Europa sinds 1945 domineert. Schubarts meest intrigerende titel is Europa und die Seele des Ostens (Europa en de ziel van het oosten) uit 1938; verder verschenen van zijn hand Dostojewski und Nietzsche. Symbolik ihres Lebens (1939), Geistige Wandlung (Geestelijke ommekeer 1940) en Religion und Eros (Religie en eros 1941). Dit vierde boek laat ik buiten beschouwing, omdat het een eigen essay verdient. Ik concentreer me op het boek over Europa en de ziel van het oosten en noem de andere publicaties wanneer deze iets toevoegen aan de centrale stelling van het meeslepende Europa und die Seele des Ostens over het heil dat Rusland heet. Dit boek droeg Schubart op aan zijn 'vrouw en kameraad Wera Markowna.'

Hoe luidt de centrale stelling van Europa und die Seele des Ostens? Schubart varieert onvermoeibaar zijn overtuiging dat de Europese mens, in het bijzonder de West-Europese mens, in zijn diepste wezen zo sterk op eigen kennis en beheersen van de natuur is gericht dat God uit de ziel van deze Europese mens is verdwenen. Ik geef een cruciale passage vertaald weer:

Wanneer de Europeaan naar zijn medemens kijkt, volgt meteen en onwillekeurig het gevoel: dit is mijn vijand. Homo homini lupus. Ieder voor zich en ieder zijn eigen God, en daarom: allen tegen elkaar en allen tegen God. Dit is het wezen en het kenmerk van het Europese samenleven. De westelijke mensen streven niet naar een gemeenschappelijk midden, ze willen juist weg van dat midden. Het meest geldt dat voor de Duitser, het minst voor de Engelsman. De Europeaan is niet alleen een egoïst in zijn dagelijkse handelen, hij is ook een metafysische egoïst. Hij is een kosmische nomade [ondeelbare entiteit], die zich afsluit van de vijandige omgeving en zich tegen haar verdedigt. [...] Hij kent alleen zichzelf werkelijk goed en wil alleen maar zichzelf kennen. De wereld heeft voor hem de betekenis van een tegenspeler of van een toeschouwer van de eigen persoon. Nooit kan deze mens afstand nemen van zichzelf. Het valt hem zwaar om te luisteren. Als hij een ander ontmoet, begint hij over zichzelf te spreken. Wanneer hij naar het welzijn van de ander vraagt, gebeurt dat uit beleefdheid en niet uit innerlijke betrokkenheid. Hij volgt de geboden van het goede gedrag en handelt niet uit een opwelling van een goed hart. Hij is bereid noch in staat om zich gevoelsmatig in een ander te verplaatsen. Hij projecteert zichzelf op de ander, als alter ego, en beoordeelt hem alsof hij het zelf was. Daarmee zeg ik niet dat hij alleen maar egoïstisch handelt. Ook de Europeaan is in staat om zich aan een ander te wijden, maar hij is niet spontaan menslievend, hij handelt niet uit een spontane emotie. Hij moet zichzelf zijn altruïstische handelingen afdwingen. (Schubart 1938:129) ${ }^{1}$

\section{Verwaand en jaloers: Europa}

Omdat de Europese mens, de mens van het Avondland, zichzelf voortdurend met de ander vergelijkt, ontstaan uit deze 'vergelijkingsmanie' twee eigenschappen: verwaandheid en jaloezie. Het mooiste, aldus Schubart, is het voor de mens Ostens (1938). van het Avondland om afgunst op te wekken, het ergste is om het voorwerp van medelijden te zijn:

Want de afgunst van de buurman bewijst diens tekortkoming, het medelijden van de buurman bewijst het gebrek van degene met wie de buurman medelijden heeft. Op grond hiervan krijgt het publieke en sociale leven van Europa dat karakter van huichelarij, stijfheid en van theatrale onoprechtheid dat de Rus daarentegen keel en hart dichtknijpt. (Schubart 1938:131)

De Europese mens, in wezen de West-Europese mens en de Rus, worden vanuit hun vermogen, respectievelijk hun onvermogen om spontaan menselijk te zijn en vanuit hun geloof in God tegenover elkaar geplaatst. Het heil moet volgens Schubart uit het oosten komen, uit Rusland in de eerste plaats. Daar is het materialisme nog niet allesoverheersend geworden en heeft zich het geloof nog weten te handhaven. Ook China wordt als land van het heil gezien, ja, in Azië als geheel ligt de geestelijke vernieuwing die Europa weer gezond zal maken:

De Rus voelt altijd de nabijheid van God en dat geeft hem bij alle belangrijke besluiten die hij neemt de zuivere vrede van de eeuwigheid. Hij vertrouwt in alles op de bovenzintuiglijke macht die het tijdelijke van binnen uit volledig bepaalt. De Rus blijft geborgen in de geruststellende eenheid van de wereld door zijn levende gevoel van verbondenheid met het geheel. Zijn alles bepalende levensgevoel is: oervertrouwen. (Schubart 1938:95)

\section{Brede cultuurhistorische penseelstreken}

Het zijn brede penseelstreken waarmee Walter Schubart het geestelijke verschil tussen het Avondland en Rusland schetst. Hij is een kind van zijn tijd in de vanzelfsprekendheid waarmee hij begrippen als 'ziel' en 'geest' inzet. Voor de sceptische mens van na 1945 is het wennen om een cultuurfilosoof zo helder omlijnd over de fundamentele zielsverscheidenheid van volkeren te horen denken. Nog sterker geldt die onwennigheid wanneer Schubart over de afwisseling van tijdperken binnen de wereldgeschiedenis spreekt. Hij spreekt over de Äonenlehre, de visie op eonen, zeer grote, van elkaar onderscheidbare tijdruimtes binnen de geschiedenis:

Voor het oog dat zich achterwaarts over de menselijke geschiedenis beweegt, krijgen afzonderlijke tijdperken scherp geprofileerde kenmerken die het geestelijk aangezicht van gemeenschappen zowel als van de afzonderlijke mens bepalen. In een eeuwige wisseling, elkander opvolgend, trachten de eonische oerbeelden, scherp omlijnde zielstypen, zich in het levende mensengeslacht te belichamen. De ontplooiing van een oerbeeld en de strijd om de hegemonie met voorgangers en opvolgers verleent de cultuurgeschiedenis haar ritme en een deel van haar spanningen en tegenstellingen. (Schubart 1938:13)

Dit oerbeeld kan volgens Schubart gehele continenten omvatten. De individuele mens moet zich oriënteren op het oerbeeld. Het oerbeeld schept het grote geestelijke kader waarbinnen zich individuen met hun eigen wensen en doelen op grond van de mate van hun zedelijke vrijheid bewegen.

Schubart gaat uit van vier oerbeelden. Hij duidt hen aan met behulp van vier trefwoorden: wereld-harmonie, 
wereldheerschappij, vlucht uit de wereld, heiliging van de wereld. De laatste vijfhonderd jaar, de tijd vanaf ongeveer 1450, domineerde volgens Schubart het prometheïsche, de geestesgesteldheid naar het voorbeeld van Prometheus. De mens met deze ziel richt zijn blik niet ten hemel, maar naar de aarde. Hij verwijdert zich steeds sterker van God en verstrikt zich steeds verder in de wereld van de materie. Secularisatie is zijn lot. Daar staat de messiaanse mens tegenover. Hem bezielt niet de wil tot macht in de geest van Friedrich Nietzsche, maar de gezindheid van de harmonie, van de liefde. Hij hakt niet in stukken om te heersen maar hij probeert om het gescheidene met elkaar te verenigen. Hij is niet vervuld van argwaan en haat, maar van een diep vertrouwen in de oergrond van de dingen. Hij ziet in de mens niet zijn vijand, maar zijn broeder, in de wereld niet zijn buit waarop hij zich stort, maar de kwetsbare stof die verlost en geheiligd moet worden. Hij wordt gedragen door een gevoel van kosmische ontroering. Hij gaat uit van de belevenis van de totaliteit. Die voelt hij in zichzelf en die probeert hij in een gefragmenteerde wereld te herstellen.

Schubart ziet de verschillende mensentypen als geestelijke oriëntaties. Daarnaast lokaliseert hij het geestelijke duidelijk in de landschappen waar de mens zijn domicilie heeft. Het belangrijkste verschil tussen de Russische en de Europese mens ziet hij in de invloed van de steppe (de Russen) tegenover de zee (de Europeanen). Deze benadering van uiteenlopende levensbeschouwingen en religieuze oriëntaties op grond van het landschap is een denkwijze die tijdens de negentiende eeuw en ook in de decennia daarna opgeld deed. Binnen de literatuurgeschiedenis maakte deze opvatting school, totdat Nazi-Duitsland deze vorm van denken omarmde en daarmee stigmatiseerde. Er lijkt zich anno 2012 een kentering aan te kondigen waarbij het denken in mentaliteiten in relatie tot landschappen weer mogelijk wordt.

\section{Prometheïsch tegenover johanneïsch}

De twintigste eeuw is voor Walter Schubart het strijdperk tussen het prometheïsche tijdperk van het afvallen van God en de beheersing der aarde enerzijds en het johanneïsche tijdperk van het Messiaanse oerbeeld dat handelt vanuit het verlangen naar heling en liefde anderzijds. Het prometheïsche verwijdert zich meer en meer van God, het johanneïsche leeft in een voortdurende innige band met Christus, met God. De wereld van Europa is in de ban van het prometheïsche, vooral Rusland, maar ook Azië in het algemeen hebben de kern van het geloof in God bewaard en vormen de kiem van de nieuwe eon. Zelfs het communisme in Sovjet-Rusland wordt binnen Schubarts denken een kracht die in weerwil van zichzelf aan de geest van het nieuwe wereldtijdperk bijdraagt.

Het zijn zeker niet de communistische machthebbers die voor Schubart de getuigen van de geestelijke vernieuwing zijn. De theoretici Karl Marx en Friedrich Engels spelen evenmin een rol als heilbrengers. De communisten hebben de ziel van de mens op de verkeerde plaats gelokaliseerd, namelijk binnen de productieverhoudingen, het eigendom van de productiemiddelen. Het heil dat uit het oosten komt, is te vinden bij denkers en schrijvers als Nikolai Berdiajev (1874-1948), Iwan Kirejevski, Vladimir Solowvov, Fjodor Tjuttschev, Nikolai Nekrassov, Sergei Aksakov, Lev Sjestov (eigenlijk: Schwarzmann) en bovenal bij de schrijver Fjodor Dostojevski. In dit rijtje namen zit geen logische volgorde. Vermoedelijk is Nikolai Berdiajew de meest invloedrijke denker geweest. Zijn pleidooi voor vereniging van christendom en marxisme maakt na zijn emigratie uit de Sovjet-Unie naar Duitsland en Frankrijk plaats voor een veroordeling van het materialisme en een keuze voor de oriëntatie op God. Al deze denkers en schrijvers hebben Walter Schubart beïnvloed. Van de filosofen was Berdiajev de belangrijkste inspiratiebron, binnen de letterkunde was het zonder twijfel Dostojevski.

\section{Dostojevski}

Aan Dostojevski is in Europa und die Seele des Ostens een apart hoofdstuk gewijd: 'Dostojewski als Gestalter des West-OstProblems.' In diens roman Schuld en boete gaat het volgens Schubart om de persoonlijke tragedie van de afvalligheid van God. In Dostojevski's De Demonen ziet Schubart de sociale tragedie van de ontrouw jegens God. Aan het slot van de weg naar het atheïstische socialisme in De Demonen staat de keuze tussen de ontbinding van de samenleving of de terugkeer naar het christendom centraal:

Dostojevski zag in dat met het socialisme en met de leer van de Übermensch de grote tegenbewegingen tegen de religie in opkomst zijn, tegenbewegingen als belijdenissen van het hier en nu, van de Diesseitigkeit zonder God, die de metafysische behoefte aan vergankelijke waarden verkwisten. (Schubart 1938:196)

In Schubarts boek over Dostojevski en Nietzsche zijn zij symboolfiguren voor twee tegengestelde levensbeschouwingen, ook al worstelen ze in eerste instantie met hetzelfde vraagstuk, met de vraag namelijk 'Wat is de mens?' Nietzsche representeert de ziel van Europa, Dostojevski die van het oosten. Al meteen aan het begin van deze studie haalt Schubart Berdiajevs uitspraak over Dostojevski aan, aantonend dat er een sterke onderlinge geestverwantschap tussen hem en Berdiajev bestond. In Dostojevsi ziet Schubart de ontmoeting van Azië en Europa op Russische bodem. Niet Moskou, maar Sint Petersburg is de plek waar de strijd zich afspeelt: Hij zag in dat de verhouding van den mensch tot God, en bijgevolg ook de verhouding van de menschen onderling, op het punt stond catastrophale veranderingen te ondergaan. (Schubart 1939:12)

In de onrust en de diepe bezorgdheid over de gang der geschiedenis zijn Dostojevski en Nietzsche verwant, maar het resultaat van hun zoektocht verschilt hemelsbreed:

Het gansche werk van Dostojevski en Nietzsche is in den diepsten grond een worstelen om God en zij onderscheiden zich slechts hierdoor van elkander, dat de een tot helder bewustzijn kwam van dezen strijd en hij den God vond, naar Wien hij zocht, terwijl de ander zichzelf en zijn weg naar God niet meer begreep en in waanzin ten onderging. (Schubart 1939:17) 
Schubart zet bij zijn vergelijking van Nietzsche en Dostojevski begrippen in die de parallel tussen beiden een tijdje kunnen volhouden. Tenslotte is het punt onontkoombaar waarop de wegen zich splitsen. Een dergelijk splijtbegrip is 'lijden.' Bij Nietzsche ontbreken volgens Schubart de zege over het lijden en de werkelijke aanvaarding van het leven. Dostojevski is door het lijden heen bij de troost uitgekomen:

Met de wereld en haar machten is hij voorgoed verzoend. Alvorens wij ze uit het diepst van ons hart aanbidden kunnen, moeten wij God en de wereld tot in den diepsten grond vervloeken. Dit is de omschrijving van den weg welke tot Dostojevski's, met heete tranen bevochten, levensaanvaarding leidt. De weg naar den hemel voert ons door de hel en daarom is het lijden, louter en alleen het lijden, de bedoeling van het leven en zijn eenige betekenis. (Schubart 1939:127)

\section{Wat is er mis met de Europese ziel?}

De strijd die in de dertiger jaren van de twintigste eeuw wordt gevoerd, is de strijd van de prometheïsche ziel tegen de johanneïsche ziel. Europa is de erfgenaam van de Verlichting vanaf de zestiende eeuw. Deze Verlichting heeft zich doorgezet, ondanks de Baroktijd met een diepe religieuze herleving en ondanks de Romantiek die een krachtige godsdienstige ondergrond had. De negentiende eeuw is de eeuw van de zelfoverschatting van de mens geworden en de twintigste eeuw - die Schubart tot 1940 kende en waar de Tweede Wereldoorlog en de vernietigingskampen nog geen deel van uitmaakten - stond in het teken van het geweld. Wat staat Walter Schubart tegen in de ziel van de Europese mens na de Middeleeuwen? Hij ziet troostloze anonimiteit als gevolg van de fanatieke strijd voor de vrije persoonlijkheid. Hij ziet in de ontwikkeling der techniek verlichting van zware arbeid en tegelijkertijd een vorm van knechting doordat de organisatie van de samenleving de mens onvrijer maakt:

Honderd jaar geleden hoopte de mens dat de machine hem - vergelijkbaar met de functie van de slaaf in de Klassieke Oudheid - zou vrijmaken voor waardige scheppingen van de geest. Maar, hoewel we vandaag de dag voor veel verrichtingen veel minder tijd nodig hebben dan onze voorouders hebben wij zeer veel minder tijd voor onszelf. (Schubart 1938:306)

Het project van de bevrijding van de mens heeft het tegendeel van vrijheid tot resultaat gehad:

Mislukt is de poging om het aardse rijk van algemene welvaart op te richten. Nooit eerder was er een cultuur als de prometheïsche die met zoveel energie en fanatisme ernaar streefde om het zintuiglijke behagen, het pure geluk van het lichaam af te dwingen, terwijl ze de zorg om het heil van de ziel uitlachte. Nooit tevoren was er een cultuur die de mens ongelukkiger en ellendiger zag dan de huidige. Om zijn doel te bereiken schiep de mens zich boven de natuurlijke ordening der dingen de vreemde, kunstmatige surrogaatwereld die wij als moderne civilisatie betitelen. Toen hij daarmee begon, zwol zijn borst van enorme gevoelens van kracht. Maar hoe verder de mechanisering voortschreed, des te sterker groeide het onbehagen in de cultuur. (Schubart 1938:305)

\section{De Russische ziel}

Wat trekt Schubart aan in de Russische ziel? In het hoofdstuk 'Kultur der Mitte und Kultur des Endes' plaatst hij de ziel van Europa tegenover de ziel van Rusland:
Vrijheid en deemoed zijn onafscheidelijk. De Rus is vrij, omdat hij deemoedig is en deemoedig is de mens die zich aan God gebonden voelt. 'Groot is Rusland door zijn deemoed' (Dostojevski). Hier kan de Europeaan de Rus niet meer begrijpen. Hij kan de begrippen deemoed en deemoediging (vernedering) niet uit elkaar houden. Wie deemoedig is, vernedert zichzelf, wie zich vernedert, is een slaaf. Hoe kan deemoed een stap naar de vrijheid zijn? Dat zijn de conclusies van de mens die zich volledig verbonden heeft met de aarde. Luther kende de deemoed nog, zelfs Napoleon had bevliegingen van deemoed, of hij deed alsof, wanneer hij zich als het instrument van het noodlot betitelde. De huidige Europeaan weet niets meer van deemoed. Hij laat de deemoed vol verachting aan de oostelijke rassen over. Omdat het Russische gevoelsleven op het einde aller dingen is gericht, begeleidt de Rus een nooit verstommend schuldgevoel. Hem bedrukt de schuld, dat hij zich nog in deze eindige wereld bevindt. [...] Terwijl de mens van het Avondland zijn best doet om zich te rechtvaardigen, zichzelf enorm op te hemelen en meer te lijken dan hij in werkelijkheid is, geeft de Rus zijn fouten en zwaktes niet alleen onomwonden toe, maar hij overdrijft ze zelfs, niet uit een ijdelheid als die van Diogenes, maar uit de behoefte aan zielkundige bevrijding. Met betrekking tot zijn persoon is hij eerlijker dan de Europeaan (met betrekking tot dingen is het omgekeerd). (Schubart 1938:91)

Met het schuldgevoel van de Rus verbindt Schubart zijn verlangen om te lijden. Schubart noemt hem de 'genieter van het lijden.' Nauw daarmee verbonden is het verdragen van ellende en nood. Met het schuldgevoel is de gedachte van het offer volgens Schubart de centrale gedachte van de Russische ethiek. Alleen het offer opent de weg die uit het aardse naar de andere wereld leidt. Zonder dood geen opstanding, zonder offer geen wedergeboorte. Dat noemt Schubart de 'Russische Paasgedachte.' Pasen en niet Kerstmis is het belangrijkste, hoogste feest binnen de Russische kerk. 'Zondag en de Opstanding hebben dezelfde naam in het Russisch en dat is geen toeval.' Aldus Walter Schubart. De Russische mens is geen mens van materiële dingen, maar de mens van de ziel.

\section{Versimpeling van de geschiedenis}

Dostojevski is een sleutelfiguur binnen Schubarts denkpatroon. Zijn romanpersonages belichamen houdingen van de Russische ziel. Terzijde zij opgemerkt dat volgens de Nederlandse theoloog Oepke Noordmans de figuren uit Dostojevski's romans de beste illustratie van Karl Barths theologie leveren. ${ }^{2}$

Behalve Dostojevski behandelt Schubart nog vele andere denkers en schrijvers in zijn boek. Ik noemde reeds N. Berdiajev, V. Solovjov, L. Sjestov en anderen. Schubart moet een immense kennis van de Russische taal en van de Russische wijsbegeerte en literatuur hebben gehad. Op mij had zijn analyse van de Russische cultuurgeschiedenis het effect dat ik me beschaamd voelde. Hoe zeer is Rusland tijdens de periode van de Koude Oorlog en ook gedurende de jaren na 1989 niet met clichés en overzichtelijke vijandbeelden genegeerd en geneutraliseerd. Hier ligt in ieder geval de winst van een hernieuwd bezig zijn met Walter Schubart. Dat sluit kritiek niet uit.

2.Mijn bron hiervoor is het proefschrift Caleidoscoop. F.M. Dostojevski en de vroege dialectische theologie door Katja Tolstaja (2006). 
Het zal niet moeilijk zijn om de zwakke kanten van Schubarts cultuurpanorama en Russische heilsverwachting te etaleren. De eonen binnen Schubarts geschiedenis van de wereld zijn zo omvangrijk en zo homogeen dat ze onrecht doen aan de complexiteit van de geschiedenis. De rooms-katholieke kerk wordt door Schubart te zeer in de luwte gehouden, terwijl het protestantisme in zijn ogen een kweekvijver van de secularisering vormt en geen goed kan doen. Aan Pruisen heeft Schubart een grote hekel waardoor hij alle historische proporties uit het oog verliest. Joden en Duitsers worden samen met de prometheïsche mens vereenzelvigd, maar dit is meer een speculatieve bewering dan een degelijke overweging. Schubart schrijft uitstekend en boeiend. Is hij eenmaal op dreef, dan lijken de woorden elkaar de hand te geven. Daarom is het slot van zijn boek waarin de voorheen zo scherp getekende tegenstelling van prometheïsch en johanneïsch wordt verzacht en afgevlakt, onbevredigend. De laatste gedeelten eisen veel geloof van de kant van de lezer, onder meer wanneer het bolsjewisme als deel van de nadering van de nieuwe heilzame eon wordt gezien. De best onderbouwde kritiek op Schubart leverde J.C. Baak met zijn boek De verhouding van den Russischen tot den WestEuropeeschen mensch uit 1945.

Baak was goed thuis in de Europese cultuurgeschiedenis en daardoor bij uitstek geschikt om Schubart van repliek te dienen, maar hij kan niet van de context van toen worden losgemaakt. Dat Baak het begrip 'ziel' vervangt door 'geest' is veelzeggend. Op deze plaats wil ik de argumenten van Baak echter niet herhalen, omdat ik de nadruk wil leggen op het verrassend actuele van een groot deel van Schubarts opvattingen. Na Baak en een kritische enkeling werd het in Nederland stil rondom Walter Schubart. De enige uitzondering is J.L. Heldring. Keer op keer heeft Heldring Schubart aangehaald in zijn columns in NRC-Handelsblad. Blijkbaar fascineert Schubarts gedachtenwereld hem, terwijl hij er zich ook weer van distantieert.

\section{Een andere ziel}

Wat is de waarde van Schubarts boek voor ons hier en nu? Schubart schrijft beeldend en hij weet grote lijnen van denken zichtbaar te maken. Hij kan het karakteristieke van bepaalde denkers als Kant, Fichte en Hegel raak benoemen, al maakt hij hen soms te klein voor wat ze waren en zijn. Deze stijl van schrijven is knap, maar uiteindelijk gaat het om de gedachten die in de bijzondere schrijfwijze zijn verpakt. Het allerbelangrijkste aan Schubarts gedachten vind ik de cultuurkritiek. Deze kritiek had ook zonder de Russische heilbrengers kunnen bestaan, zelfs met een imaginaire drager van andere dan de Europese waarden. Ik wil daarbij niet Schubarts ritmiek van de wereldgeschiedenis verstoren. Die ritmiek kan ik intact laten, terwijl ik een andere tegenstander bij de kop heb. Wanneer ik Schubart lees, ook zijn boek over geestelijke bekering en de studie van de tegenstelling tussen Dostojevski en Nietzsche, voel ik dat Schubart aan de huidige westerse cultuur een spiegel voorhoudt. Zijn pleidooi voor het zwijgen en de stilte is balsem voor de ziel van degene die zich uitgeleverd voelt aan het misbruik van de taal op de televisie en via de zogenaamde sociale media. West-Europa beleeft anno 2012 een ongekende welvaart, maar erg tevreden zijn de profiteurs van de welvaart niet. Dat de mens een wolf is voor andere mensen, is dagelijks op straat te ervaren waar de voetganger en de fietser worden belaagd door de automobilist in zijn autistische cocon. Nooit eerder was er zoveel materiële welvaart en desondanks blijft de behoefte aan meer materie bestaan. Een ontspannen tevredenheid en bestaanszekerheid is ver te zoeken. De door Schubart genoemde angst is alom. Het vertrouwen in God die de Schepping onderhoudt, heeft plaats gemaakt voor een apocalyptische vrees dat het spoedig afgelopen zal zijn. De vrees voor de toekomst gaat gepaard met het gevoel van schuld over de uitbuiting van deze wereld en de minachting jegens de andere schepselen. Het is de hoogste tijd dat wij mensen ons bekeren en anders gaan leven en voelen, en het is deze oproep die spreekt uit het werk van Walter Schubart. We kunnen zijn eonen-leer als het product van een overspannen geest beschouwen en ons er niets van aan trekken. We kunnen zijn synthese ook als een moedige poging zien om niet versnipperd te denken, maar te proberen tot de diepste waarheid, de ziel, van onze cultuur en van onszelf door te dringen.

Bij het lezen van Schubarts werk besefte ik tot mijn schrik dat vele grote Russische denkers tot nu toe buiten mijn gezichtsveld zijn gebleven. Hoeveel spirituele rijkdom heeft West-Europa zich nodeloos ontzegd! Geldt hetzelfde niet voor China? Waar wachten wij nog op?

\section{Erkenning Tegenstrijdige belangen}

De auteur verklaart geen financiële of persoonlijke belangen te hebben die hom ongepast kunnen hebben beïnvloed bij het schrijven van dit artikel.

\section{Literatuurverwijzingen}

Baak, J.C., [1945] 1946, De verhouding van den Russischen tot den West-Europeeschen mensch. Aan de hand van een critische beschouwing over Walter Schubart's 'Europa und die Seeles des Ostens', Uitgeverij W. Ten Have, Amsterdam.

Schubart, W., 1938, Europa und die Seele des Ostens, Vita Nova Verlag, Luzern.

Schubart, W., 1939, Dostojewski en Nietzsche. De symboliek van hun leven, vert. W.J. Merckens, Uitgeverij De Librije, Overveen.

Schubart, W., 1940, Geistige Wandlung. Von der Mechanik zur Metaphysik, Vita Nova Verlag, Luzern.

Schubart, W., 1941, Religion und Eros, Beck'sche Verlagsbuchhandlung, München.

Tolstaja, K., 2006, Caleidoscoop. F.M. Dostojevski en de vroege dialectische theologie, Theologische Uitgeverij Narratio, Gorinchem. 